\section{Small-intestinal cancer arising from heterotopic} pancreas

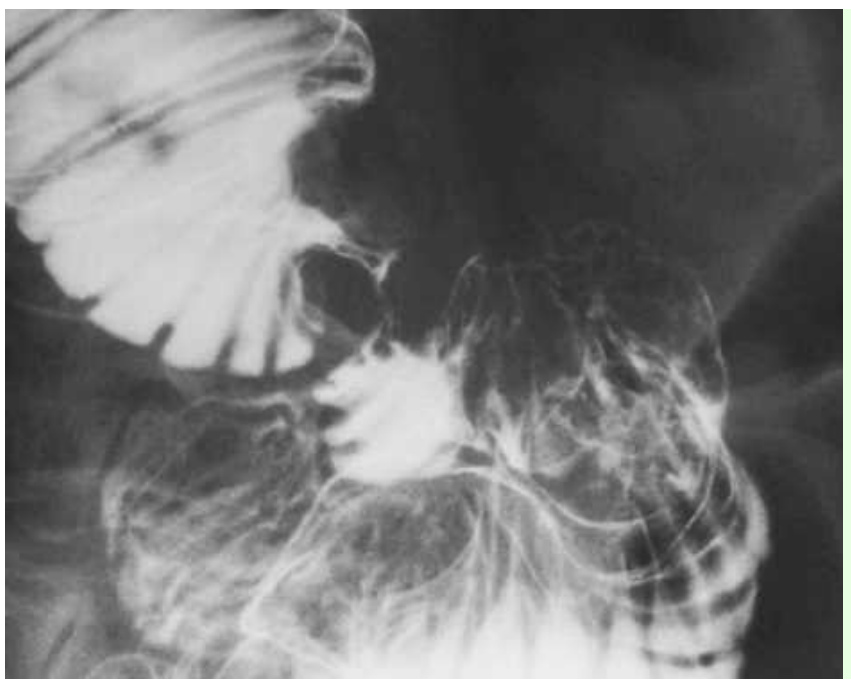

Fig. 1 Small-bowel radiography shows a protrusion with smooth margin accompanied by stenosis in the jejunum. There were barium flecks and fold convergences in the anal side of the stenosis.

We report on a case of jejunal cancer arising from heterotopic pancreas, as depicted by small-bowel radiography and double balloon endoscopy.

A 64-year-old woman was admitted to our hospital with abdominal distension and epigastric pain. Small-bowel radiography with double contrast study showed a stenosis in the jejunum and a dilatation of the proximal small intestine ( Fig. 1). Oral double balloon endoscopy showed a smooth, ulcerating tumor that involved the jejunum circumferentially ( Fig. 2). Under laparotomy, a solid mass was seen with a stenosis about $45 \mathrm{~cm}$ distal to the ligament of Treitz. Intraoperative enteroscopy from the anal side of the stenosis revealed a nodular and friable tumor with an ulcer ( $\bullet$ Fig. 3). The segment of the jejunum containing the tumor together with some enlarged lymph nodes were removed.

Macroscopically, there was a mass with an umbilication and an irregular ulcer, which was covered with normal mucosa ( Fig. 4). Histologically, there was pancreatic tissue within the submucosa and the muscularis propria in the proximal part of the tumor, and adenocarcinoma cells were seen peripherally in the pancreatic tissue ( $\bullet$ Fig. 5 and $\mathbf{6}$ ). These findings were compatible with the diagnosis of adenocarcinoma originating from heterotopic pancreas. Although we treated the patient by chemotherapy with gemcitabine, she died as a result of carcinomatous peritonitis 5 months after the surgery.

Although extremely rare, there have been cases in which small-intestinal heterotopic pancreas was presumed to have transformed into adenocarcinoma [1-3]. The images from our case can be summarized

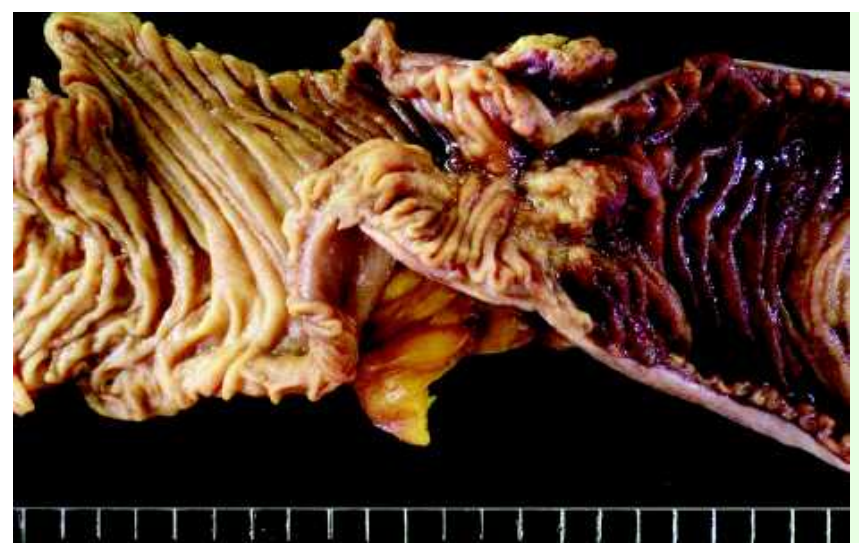

Fig. 4 A macroscopic view of the resected specimen shows that the tumor with an umbilication is covered by normal mucosa.

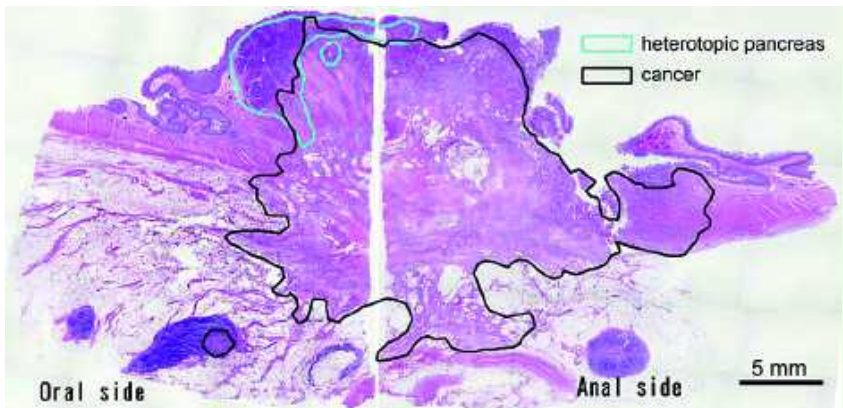

Fig. 5 Histologic examination of the specimen shows that the tumor is composed of areas of heterotopic pancreas (surrounded by blue line) and adenocarcinoma (surrounded by black line). 


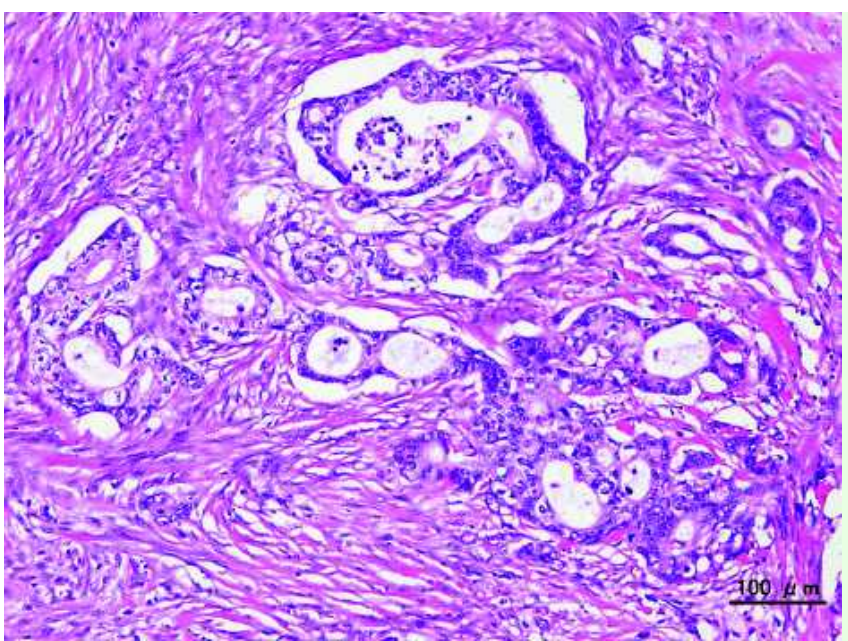

Fig. 6 A high-power view of the carcinomatous area indicates that the cancer cells are arranged in tubular and cribriform patterns with abundant fibrous stroma.

as asymmetrical luminal narrowing with a smooth tumor in the oral side and an ulcerating nodular tumor in the anal side. Our case suggests that enteroscopists should regard heterotopic pancreas as a possible premalignant lesion.

Endoscopy_UCTN_Code_CCL_1AC_2AC
K. Fujita ${ }^{1}$, K. Hirakawa ${ }^{1}$, T. Matsumoto ${ }^{2}$, K. Amano ${ }^{1}$, S. Yanai ${ }^{1}$, S. Fujioka ${ }^{1}$, Y. Himeno ${ }^{1}$, K. Motoyama ${ }^{3}$,

Y. Nakashima ${ }^{4}$, M. lida ${ }^{2}$

1 Division of Gastroenterology, Fukuoka Red Cross Hospital, Fukuoka, Japan

2 Department of Medicine and Clinical Science, Graduate School of Medical Sciences, Kyushu University, Fukuoka, Japan

3 Division of Surgery, Fukuoka Red Cross Hospital, Fukuoka, Japan

${ }^{4}$ Division of Pathology, Fukuoka Red Cross Hospital, Fukuoka, Japan

\section{References}

1 Persson GE, Boiesen PT. Cancer of aberrant pancreas in jejunum. Case report. Acta Chir Scand 1988; 154: 599-601

2 Makhlouf HR, Almeida JL, Sobin LH. Carcinoma in jejunal pancreatic heterotopia. Arch Pathol Lab Med 1999; 123: 707-711

3 Arao J, Fukui H, Hirayama D et al. A case of aberrant pancreatic cancer in the jejunum. Hepatogastroenterology 1999; 46: $504-$ 507

Bibliography

DOI $10.1055 / \mathrm{s}-2008-1077693$

Endoscopy 2008; 40: E240-E241

(c) Georg Thieme Verlag KG Stuttgart · New York . ISSN 0013-726X

Corresponding author

\section{K. Fujita, MD}

Department of Anatomic Pathology

Graduate School of Medical Sciences Kyushu University

Maidashi 3-1-1

Higashi-ku

Fukuoka 812-8582

Japan

Fax: +81-92-6425968

kfujita@surgpath.med.kyushu-u.ac.jp 